\title{
Düzce İlinde Yırtıcı Memeli Türlerin Zamansal ve Mekânsal Dağılımı
}

\author{
Akif KETEN \\ Düzce Üniversitesi Orman Fakültesi Yaban Hayatı Ekolojisi ve Yönetimi Bölümü \\ Sorumlu yazar: akifketen@duzce.edu.tr
}

Geliş Tarihi: 20.10.2016

\begin{abstract}
Özet
Popülasyonların dengede tutulmasında önemli bir yeri olan yırtıcı memeli türler bulundukları yaşam alanlarında tüketici rolünde besin piramidinin üstünde yer almaktadır. Bu çalışma Düzce ilindeki yırtıcı memeli türlerin mekânsal ve zamansal yayılışlarını ortaya koymak amacıyla yapılmıştır. Çalışma 2013 ve 2015 yıllarında toplam 234 noktada farklı habitatlarda doğrudan, dolaylı gözlemler ve fotokapanlarla yapılmıştır. Toplam 4 familyadan 10 türe ait 660 birey sayılmış ve 56 belirti tespit edilmiştir. En yaygın tür kızıl tilkidir. Türler genellikle gececil davranmaktadır. Ormanlık alanlar ana yaşam alanlarını oluşturmaktadır. En fazla saf kayın ve kayın karışık ormanları tercih etmektedirler. Türlerin yaşam alanlarında yapılacak insan faaliyetlerinin dikkatli yapılması türler için faydalı olacaktır.
\end{abstract}

Anahtar kelimeler: Yaban hayatı, Fotokapan, Kız1l tilki, Orman

\begin{abstract}
Spatial and temporal distribution of Carnivora (Mammalia) species in Düzce Province
Abstract

Carnivores species play essential roles in ecosystem structuring and stability, are positions at the top of food webs in their habitats. The current study is to aim to exhibit that spatial and temporal distribution of Carnivores (Mammalia) species in Düzce Province. The study was carried by wildlife camera traps and direct or indirect observation methods on different habitats in a total of 234 sampling plots in 2013 and 2015 years. A total of 660 specimens were counted from 10 species in 4 families, and 56 tracks were determined. The most common species is red fox. The species are generally nocturnal. Their main home range is forest areas. They prefer mostly to pure and mix beech stand. To be careful of the human activities in habitats of carnivores is suggested for their.
\end{abstract}

Keywords: Wildlife, Camera trap, Red fox, Forest

Giriș

Yrrtıc1 memeli (Carnivora) türler bulundukları yaşam alanlarında tüketici rolünde besin piramidinin üstünde yer almaktadır. Popülasyon düzeyleri avladıkları hayvanlardan daha düşük olup onlardan daha geniş alanlarda yayılış göstermektedir (Ripple ve ark., 2014). Geçmişte her ne kadar ekolojik değerleri önemsiz olduğu düşünülse de günümüzde popülasyonların dengede tutulmasında önemli bir yeri olduğu bilinmektedir (Miller ve ark, 2001). Diğer taraftan az da olsa ekonomik zararlara sebep olma, doğrudan insana saldırı (Ambarlı ve Bilgin 2008), hastalik yayma (Capinera, 2011) gibi olumsuzlukları da bulunmaktadır. Carnivora takımı ülkemizin bulunduğu Paliarktik bölgede yedi familya; Canidae, Felidae, Hyaenidae, Mustelidae, Ursidae, Viverridae ve Procyonidae ile temsil edilmektedir. Türkiye'de yapılan çalışmalarda Canidae, Felidae, Hyaenidae, Mustelidae ve Ursidae familyalarına ait 18 türün kaydı bulunmaktadır (Kumerloeve, 1978; Albayrak ve ark., 1997).

Ülkemizde küçük alanlarda (Can ve Togan, 2009; Hızal, 2008), iller bazında (Çam ve Ölmez 2015; Toyran, 2016) ve bölgesel (Özkurt ve ark., 1998; İbiş ve ark., 2015) olarak yırtıcı memelilerin tespitine yönelik çalışmalar yapılmıştır. $\mathrm{Bu}$ çalışma Düzce ilindeki yırtıcı memeli türlerin mekânsal ve zamansal yayılışlarını ortaya koymayı amaçlamaktadır.

\section{Materyal ve Metod \\ Çalışma alanı}

Düzce ili Batı Karadeniz bölgesinin batı sınırını oluşturmaktadır (Şekil 1). Toplam yüzölçümü Düzce Valiliği verilerine göre 
değişik kaynaklarda farklı değerler (241 000364000 ha) verilse de Bolu Orman Bölge Müdürlüğü verilerine göre 123814 ha (\%51) ormanlik alan bulunmaktadir. Ormanlar Karadeniz iklimi etkisinde yapraklı (Kayın, Gürgen, Meşe, Kestane, Ihlamur), ibreli (Göknar, Sarıçam, Karaçam) ve bunların karışımından oluşmaktadır. Orman alanları yüksek eğim grubundaki yerlerde bulunmakta ve deniz kenarından $1830 \mathrm{~m}$ (Kardüz Yaylası)'ye kadar çıkmaktadır. Orman alanlarının bitişiğinde bulunan findıklıklar yaklaşık 62000 ha'dır. Ortalama sicaklığ $13.3{ }^{\circ} \mathrm{C}$, ortalama yağı $816 \mathrm{~mm}(1950$ 2014)'dir. İklim tipi (Thornthwaite'a göre); Nemli, Mezotermal Su noksanı yaz aylarında orta dereceli, Yaz buharlaşma oranı \%51 (B1,B'2,s,b'4)'dir (Anonim, 2016).

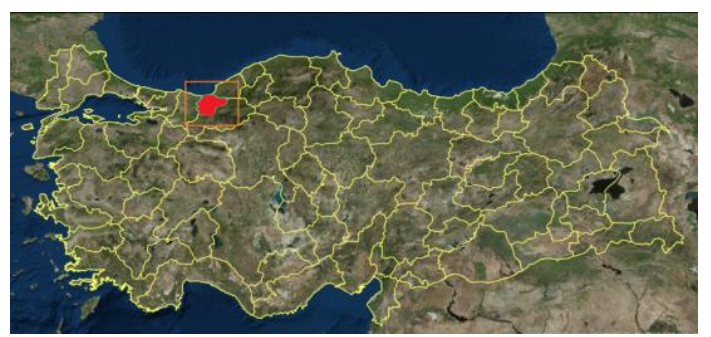

Şekil 1. Çalışmanın yapıldığı Düzce ili

\section{Veri toplama}

Çalışma 2013 yılında 87 ve 2015 yıllarında 147 nokta olmak üzere toplam 234 noktada yapılmıştır. Örnekleme yapılan noktalarda doğrudan, dolaylı (iz, dışkı, yiyinti vb.) ve fotokapanlarla gözlem yapılmıştır. Son y1llarda karasal memeli türler ile ilgili arazi çalışmalarında fotokapanlar yaygın olarak kullanılmakta ve diğer metodlar kadar kullanışlı olduğu belirtilmektedir (Roberts, 2011). Örneklemede fotokapan çalışma süreleri eşit olmadığından 100 günlük sabit süre için veriler dönüştürülmüştür. Bunun için; $100 \mathrm{x}$ yırtıcı memeli görüntü sayıs1/Fotokapan gün sayıs1 formülü uygulanmıştır (Kinnaird ve O'brien, 2012). Fotokapan ile 2013 y1lında tüm noktalarda ve 2015 yılında 94 noktada çalışılmıştır. Farklı habitat tipleri taranmış ve türlerin bulunabileceği muhtemel alanlar gözlenmiş ve uygun alanlara en az 15 gün süre kalacak şekilde fotokapan kurulmuştur. Türün görüldüğü ve fotokapan ile belirlendiği noktalar sayısal harita üzerine ișlenmiștir. Elde edilen fotokapan görüntülerinden tarih ve saat bilgileri not edilmiştir.

\section{Bulgular}

Yırtıcı memeli türler, çalışmanın yapıldığ 1 iki y1l içerisinde 234 noktada (Şekil 2) Carnivora takımından 10 tür tespit edilmiştir (Tablo 1). 2013 y1lındaki tüm gözlem noktalarında, 2015 yılında ise 94 noktada fotokapanla 4243 fotokapan günü gözlem yapılmış ve toplam 660 birey sayılmıştır. Yapılan çalışmalarda 5 noktadan görüntü alınamamıștır. En yaygın ve sık görülen tür kızıl tilki ve altın çakal iken vaşak sadece bir kez tespit edilmiş ve görüntülenebilmiştir. 100 gün üzerinden hesaplandığında Düzce geneli için görüntülenme frekans1 15.6 olarak hesaplanmıştır. Türler çoğunlukla tekli yaşamakta olup çalışmada grup ortalama birey say1s1 $1.076 \pm 0.36$ (SD) olarak hesap edilmiştir. Kızıl tilki, kaya sansarı, altın çakal ve bozayı diğer türlere göre daha geniş alanlarda gözlenmiştir. Dolaylı gözlemlerle de benzer olarak en fazla kızıl tilki belirlenmiştir. 


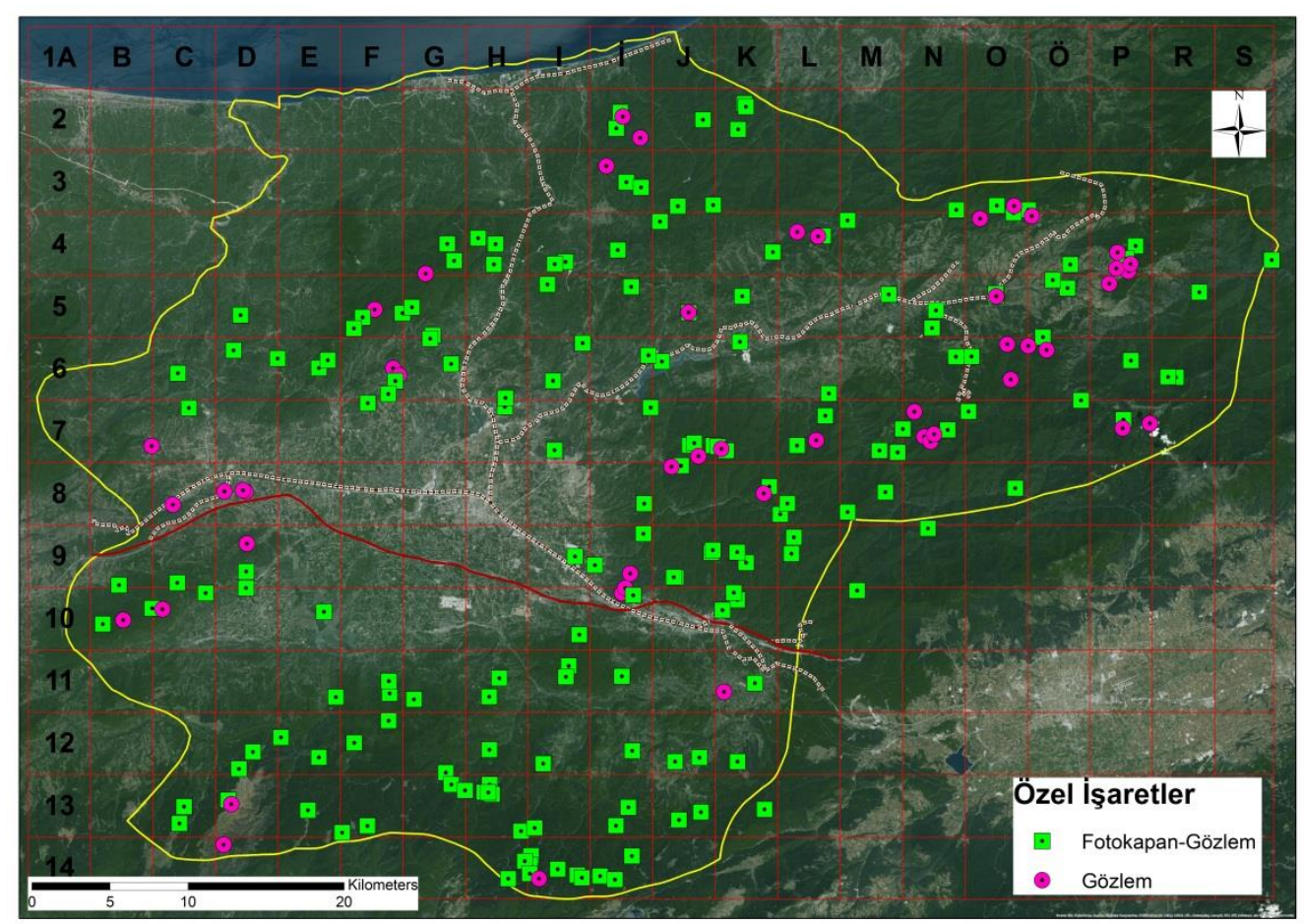

Şekil 2. 2013 ve 2015 yıllarında tür tespit çalışması yapılan noktalar

Tablo 1. Türlerin tespit edildiği alanlardaki birey sayıları

\begin{tabular}{lllccccc}
\hline Familya & Tür & Türkçe adı & $\begin{array}{l}\text { Nokta } \\
\text { sayısı }\end{array}$ & $\begin{array}{l}\text { Fotokapan ile } \\
\text { sayılan birey } \\
\text { sayısı }\end{array}$ & $\begin{array}{l}\text { 100 gün } \\
\text { görüntü } \\
\text { sayısı }\end{array}$ & $\begin{array}{l}\text { Dolaylı } \\
\text { gözlem (İz, } \\
\text { dışkı) }\end{array}$ & $\begin{array}{l}\text { Sayılan } \\
\text { toplam } \\
\text { birey }\end{array}$ \\
\hline Canidae & Canis aureus & Altın çakal & 40 & 126 & 2.95 & 13 & 138 \\
Canidae & Canis lupus & Kurt & 15 & 42 & 0.99 & 6 & 48 \\
Canidae & Vulpes vulpes & Kizıl tilki & 77 & 277 & 6.55 & 15 & 293 \\
Felidae & Felis silvestris & Yaban kedisi & 19 & 29 & 0.68 & 0 & 29 \\
Felidae & Lynx lynx & Vaşak & 1 & 1 & 0.02 & 0 & 1 \\
Mustelidae & Lutra lutra & Su samuru & 2 & 1 & 0.02 & 1 & 2 \\
Mustelidae & Martes foina & Kaya sansarı & 58 & 106 & 2.50 & 7 & 113 \\
Mustelidae & Meles meles & Porsuk & 8 & 11 & 0.26 & 0 & 11 \\
Mustelidae & Mustela nivalis & Gelincik & 3 & 2 & 0.05 & 1 & 3 \\
Ursidae & Ursus arctos & Bozayı & 39 & 65 & 1.53 & 13 & 78 \\
Toplam & & & 234 & 660 & 15.56 & 56 & 716 \\
\hline
\end{tabular}

Yırtıcı memeliler gün içerisinde daha çok gece görüntülenmiştir. Tür sayısı ve toplam birey sayısı gün batımı ile artmakta ve gün aydınlığında azalmaktadır (Tablo 2). Ancak günün her saatinde sinırlı da olsa türler aktivite göstermektedir (Şekil 3). Tüm yırtıcı türler zamansal olarak benzer davranışları göstermektedir. Yırtıcıların mekânsal olarak önemli göçler göstermediğinden mevsimsel olarak değerlendirme yapılmamıştır. 
Tablo 2. Tür sayısının ve yaygın olan türlerin günün saatlerine göre dağılımı

\begin{tabular}{lcccccc}
\hline Saat & Tür sayısı & K. tilki & A. çakal & K. sansarı & Bozayı & Diğer \\
\hline 00:00-00:59 & 6 & 17 & 8 & 4 & 2 & 7 \\
01:00-01:59 & 7 & 9 & 5 & 8 & 3 & 4 \\
02:00-02:59 & 7 & 17 & 7 & 5 & 2 & 11 \\
03:00-03:59 & 5 & 16 & 7 & 15 & 1 & 3 \\
04:00-04:59 & 7 & 10 & 7 & 13 & 1 & 8 \\
05:00-05:59 & 5 & 22 & 10 & 3 & 2 & 5 \\
06:00-06:59 & 5 & 15 & 6 & 4 & 4 & 11 \\
07:00-07:59 & 5 & 18 & 4 & 2 & 1 & 1 \\
08:00-08:59 & 4 & 13 & 5 & 1 & 2 & 0 \\
09:00-09:59 & 4 & 7 & 1 & 1 & 7 & 0 \\
10:00-10:59 & 4 & 6 & 5 & 0 & 1 & 2 \\
11:00-11:59 & 3 & 3 & 0 & 2 & 2 & 0 \\
12:00-12:59 & 3 & 4 & 0 & 0 & 3 & 1 \\
13:00-13:59 & 4 & 2 & 1 & 1 & 0 & 1 \\
14:00-14:59 & 1 & 4 & 0 & 0 & 0 & 0 \\
15:00-15:59 & 5 & 4 & 0 & 1 & 1 & 2 \\
16:00-16:59 & 2 & 7 & 0 & 2 & 0 & 0 \\
17:00-17:59 & 5 & 7 & 1 & 2 & 0 & 3 \\
18:00-18:59 & 4 & 13 & 4 & 4 & 2 & 0 \\
19:00-19:59 & 6 & 17 & 7 & 2 & 4 & 9 \\
20:00-20:59 & 8 & 18 & 19 & 8 & 6 & 7 \\
21:00-21:59 & 5 & 17 & 9 & 7 & 6 & 4 \\
22:00-22:59 & 7 & 18 & 11 & 11 & 7 & 7 \\
23:00-23:59 & 5 & 12 & 9 & 10 & 8 & 1 \\
\hline & & & & & &
\end{tabular}

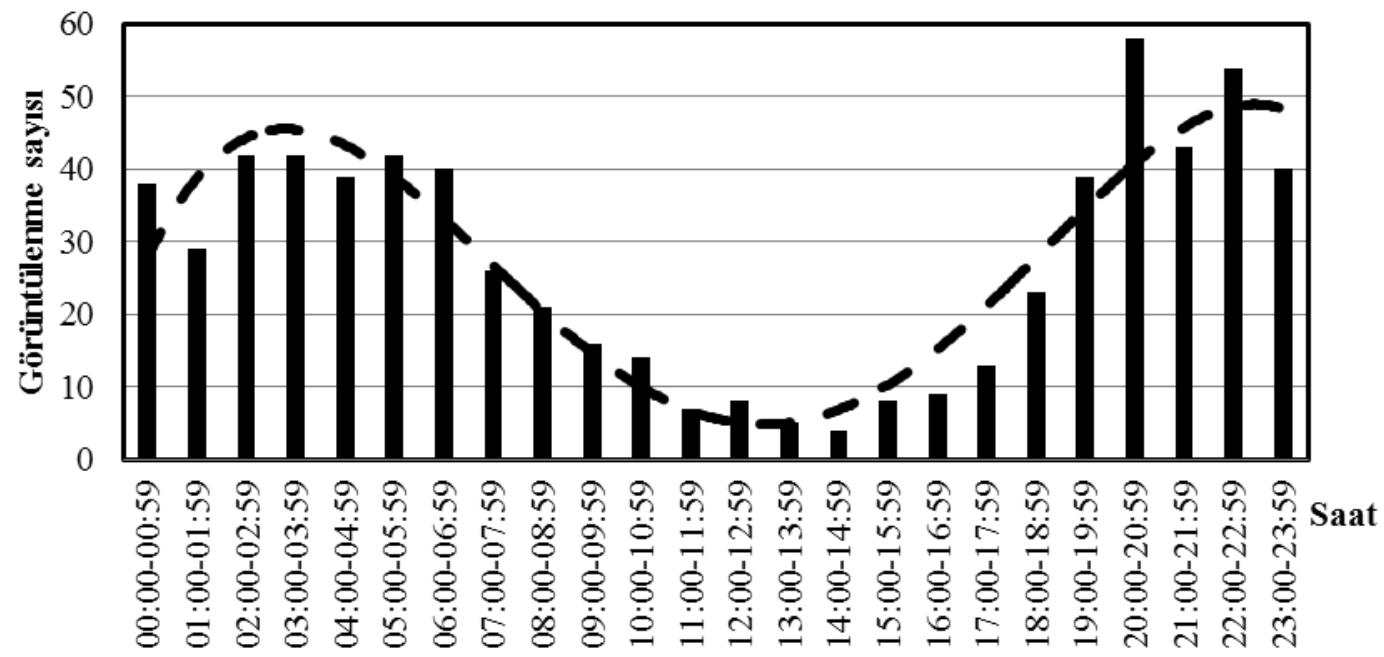

Şekil 3. Fotokapanla tespit edilen bireylerin gün içerisindeki görüntülenme sayıları

Yırtıcı memeli türler farklı meșcere tiplerinde görüntülenmekle beraber yapraklı ormanlarda daha fazla gözlenmiştir (Şekil 4). Özellikle saf kayın ve kayın karışık meşcerelerde daha yüksek tespit edilmiştir. Türler ibreli ormanları oldukça az tercih etmiş tarım alanlarında ise bir kez belirlenmiştir. Denizden 65-1720 m arasında çoğunlukla 
ormanlık alanlarda yaşayan bu türler, Batı Karadeniz bölgesindeki Yenice, Küre dağları gibi büyük yaşam alanları ile bağlantısı olan Yedigöller ve yakın yöresinde siklıkla görülebilmektedir. Diğer taraftan Samanlı dağlarındaki ormanlı alanlarda da varlıklarını devam ettirmektedir.

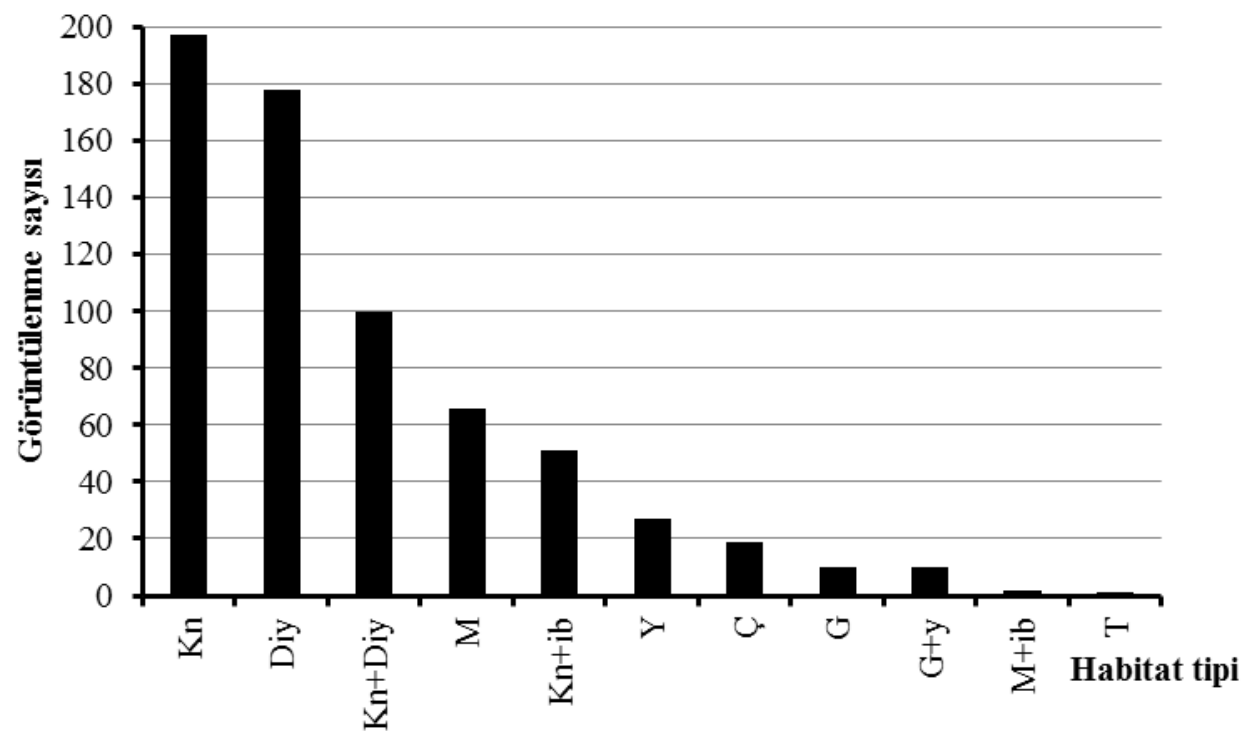

Şekil 4. Karaca'nın 100 fotokapan günündeki görüntülenme sayısının meşcere ağaç türlerine göre dağılımı (Kn: Kayın, M: Meşe, G: Göknar, Ç: Çam, Diy: Diğer yapraklı, ib:İbreli, Y:Yerleşim, T: Tarım)

\section{Tartıșma ve Sonuc}

Düzce alansal olarak küçük bir il olmasına rağmen ülkemizde varlığı bilinen yırtıc1 memeli türlerin çoğuna $(\% 56)$ yaşam alanı oluşturmaktadır. İçinde bulunduğu Batı Karadeniz bölgesindeki tüm yırtıcı memeli türleri barındırmaktadır (Küçük, 2012, Özkazanç 2012; Ünal, 2012; Çam ve Ölmez, 2015). Bunun en önemli etkisi tipik bölge habitatlarını içermesi ve bölgedeki Yenice ormanları, Küre dağları, Ilgaz dağları gibi büyük yaşam alanlarına ekolojik koridorlarıyla bağlı olmasıdır. Karakulak, kuyruk süren, sırtlan gibi yırtıcı türlerin alanda bulunmaması bu türlerin habitat isteklerinin tamamen farklı olmasından kaynaklanmaktadır.

Yırtıc1 memeli türlerinin, yaşam alanlarının diğer türlere göre geniş olması, gececil davranmaları, sayım metodlarının zor uygulanması (van de Kerk ve ark., 2013), vaşak, su samuru, kurt gibi türlerin genel popülasyon düzeylerinin düşük olması gibi nedenlerden dolayı yırtıcı türlerinin popülasyonlarının tam olarak ortaya konulması güçtür. Ancak bu çalışmadaki gibi yapılan örneklemeler en azından hem takım içerisinde hem de diğer gruplarla olan popülasyon oranları hakkında fikir verebilmektedir.

Alandaki en yaygın tür olan kızıl tilkinin yaşam alanlarında uyum yeteneği fazladır. Besin bulabildiği sürece ormanlar, açık alanlar ve yerleşim yerlerine yakın bölgelerde yaşar (Mitchell-Jones ve ark., 1999). Diğer yaygın tür olan altın çakal, şekil ve yaşam alanları bakımından k1zıl tilkiye benzemektedir. Besin bakımından firsatçı olan tür çoğunlukla küçük memeliler ile beslenmektedir (Cirovic ve ark., 2014). Her ne kadar kaya sansarının birey sayısı az belirlense de kızıl tilkiden sonra en fazla noktada yayılışı bulunmaktadır. Bozayı ve kurt diğer türlere göre hem teritori alanları hem de yaşam alanları daha geniştir. $\mathrm{Bu}$ nedenle daha düşük popülasyon seviyelerinde olmaktadır (Beşkardeş, 2016). Yerel halk tarafından gelincik türünün yoğun olduğu söylenmesine rağmen çalışmada fazla tespit edilememiștir. Su samuru sulak alanlara ve bu alanlardaki özellikle balık popülasyonlarına bağımlı yaşaması türün az tespit edilmesine 
neden olmuştur. Vaşak Batı Karadeniz bölgesinde nadiren tespit edilebilmektedir. Çalışmada da sadece bir alandan kaydı verilmiştir.

Bozay1, kurt, yaban kedisi, vaşak ve porsuk türleri büyük ve parçalanmamış orman alanlarına ihtiyaç duymaktadır (Gittleman, 1985). Bu türler çoğunlukla Düzce ilinde Yedigöller ve Samanlıdağları bölgesinde yaşamaktadır. Bu alanları beslenme, üreme, kışlama gibi ihtiyaçlarını karşılamada kullanmaktadır. Bu türlerin daha çok gececil olmaları insan faaliyetlerinden kaçınmak için de kullandıkları bir strateji olarak kabul edilebilir. İnsan faaliyetleri yaban hayvanları dikkate alınarak gündüz dikkatli biçimde yapılmas1, gece ise mümkünse yapılmamas1 gerekir. Özellikle yapraklı orman alanlarında yapılacak ormancılık faaliyetleri mümkün olduğunca hızlı ve doğal tahribata sebep olmadan yapılmalıdır.

\section{Teșekkür}

$\mathrm{Bu}$ çalışma Düzce Üniversitesi Bilimsel Araştırma Projeleri (DÜ-BAP) tarafindan desteklenmiştir. Çalışmada desteklerini gördüğüm Dr. Vedat BEŞKARDEŞ, A. Salih DEĞERMENCİ, Cemil SERT ve İlhami TURAN'a teşekkür ederim.

\section{Kaynaklar}

Albayrak İ, Pamukoğlu N, Aşan N, 1997. Bibliography of Turkish Carnivores (Mammalia: Carnivore). Communication Fas. des. Scien. de L univ. d-Ankara. Series C, 15, 1-20.

Ambarl1, H., Bilgin, C.C. 2008. Human-brown bear conflicts in Artvin, northeastern Turkey: Encounters, damage, and attitudes. Ursus, 19(2), 146-153.

Anonim, 2016. http://www.mgm.gov.tr/. Düzce iklim verileri. [Ziyaret: 17.02.2016]

Beşkardeş, V. 2016. Yedigöller Yaban Hayatı Geliştirme Sahasındaki İri Cüsseli Memeli Hayvanlar ve Sonbahar Dönemi Habitat Tercihleri Düzce Üniv. Ormanc1lık Dergisi, 12(1), 137-144.

Can, Ö.E., Togan, İ. 2009. Camera trapping of large mammals in Yenice Forest, Turkey: local information versus camera traps. Oryx, 43(03), 427-430.

Capinera, J. 2011. Insects and wildlife: arthropods and their relationships with wild vertebrate animals. John Wiley \& Sons.

Ćirović, D., Penezić, A., Milenković, M., Paunović, M. 2014. Winter diet composition of the golden jackal (Canis aureus L., 1758) in Serbia.
Mammalian Biology-Zeitschrift für Säugetierkunde, 79(2), 132-137.

Çam, P., Ölmez, İ. 2015. Sinop İli Memeli Hayvan Faunasının Değerlendirilmesi. Iğdır Univ. J. Inst. Sci. \& Tech. 5(3), 9-16

Gittleman, J.L. 1985. Carnivore body size: ecological and taxonomic correlates. Oecologia, 67(4), 540-554.

Hızal, E. 2008 Kapıdağ Yarımadası Memeli (Mammalia) Faunası. Bartın Orman Fakültesi Dergisi. Cilt: 10, Say1: 14, S.: 22-32

İbiş, O., Aksöyek, E., Özcan, S., Tez, C. 2015. A preliminary phylogenetic analysis of golden jackals (Canis aureus)(Canidae: Carnivora: Mammalia) from Turkey based on mitochondrial D-loop sequences. Vertebr Zool, 65, 391-397.

Kinnaird, M.F., O'brien, T.G., 2012. Effects of Private-Land Use, Livestock Management, and Human Tolerance on Diversity, Distribution, and Abundance of Large African Mammals. Conservation Biology, 26(6), 1026-1039.

Kumerloeve, H. 1978. Türkiye'nin memeli hayvanlar1. Journal of the Faculty of Forestry Istanbul University (JFFIU), 28(1), 178-204.

Küçük, Ö. 2012. Taşköprü Orman İşletme Müdürlüğü'nün Yaban Hayatı Potansiyeli ve Değerlendirilmesi. Bilimsel Rapor. Kastamonu Üniv. Orman Fakültesi

Miller, B., Dugelby, B., Foreman, D., del Rio, C.M., Noss, R., Phillips, M., Reading, R., Soulé, M E., Terborgh, J., Willcox, L. 2001. The importance of large carnivores to healthy ecosystems. Endangered Species Update, 18(5), 202-210.

Mitchell-Jones, A.J., Amori, G., Bogdanowicz, W., Kryštufek, B., Reignders, P.J.H., Spitzenberger, F., Stubbe, M., Thissen, J.B.M., Vohralik, V., Zima, J. 1999. The Atlas of European Mammals, Academic Pres., London, 085661-130-1.

Özkazanç, N.K. 2012. Sökü Yaban Hayatı Koruma Alanı'nda Tespit Edilen Büyük Memeli Hayvanlar. Uluslararası Bartın Orman Fakültesi Dergisi, 14(21), 92-99.

Özkurt, Ş., Sözen, M., Yiğit, N., Çolak, E. 1998. Notes on distributional records and some characteristics of five carnivore species (Mammalia: Carnivora) in Turkey. Turkish Journal of Zoology, 22(4), 285-288.

Ripple, W.J., Estes, J. A., Beschta, R. L., Wilmers, C.C., Ritchie, E.G., Hebblewhite, M., Berger, J., Elmhagen, B., Letnic, M., Nelson, M.P., Schmitz, O.J., Smith, D.W., Wallach, A.D., Schmitz, O.J. 2014. Status and ecological effects of the world's largest carnivores. Science, 343(6167), 1241484.

Roberts, N.J., 2011. Investigation into survey techniques of large mammals: surveyor 
competence and camera-trapping vs. transectsampling. Bioscience Horizons, 4(1), 40-49

Toyran, K. 2016. Predatory Mammal Species of Bitlis Province (Mammalia: Carnivora Iğdır Univ. J. Inst. Sci. \& Tech., 6(2), 27-32

Ünal, S. 2012. Yenice fauna raporu. Kastamonu Üniv. Orman Fakültesi

van de Kerk M, de Kroon H, Conde DA, Jongejans, E. 2013. Carnivora Population Dynamics Are as Slow and as Fast as Those of Other Mammals: Implications for Their Conservation. PLoS ONE 8(8), e70354. doi:10.1371/journal.pone.0070354 